ORIGINAL PAPERS

報 文

(38)
誉次近似法による多成分采第液平衡関係式の表現と 多成分系共沸物の解析について*

\section{1. まえがき}

蒸溜計算にあたって H.T.U., 段奻勔などをはじめ種 々重要な項目が考えられるが，蒸溜系がすつところの気 夜平衡関係の把握があくまで計算の基碟となることは周 知のところである。さてその関係の把握沉あたってて実 即によることが望むしいが，あらゆる条件について实験 的にその関係を求めることは頻雑で不可能に近い。そこ でこれらの関係について数多くの人々によって研究が行 われ，そのうちでも van Laar，Margules の式などは あまりにも著名である。2成分系平衡関保の解析につい てはすで数多くの研究がある。とくに平田氏”によっ てなされたその基磷的解析は著名なるのである。しかし 多成分采気液平衡関係については気液の分析化学的方法 その他その取扱いの频雑さから，その発表はきわめて少 なくまとまった研究としては Wohl 氏2》の研究を基にし たところの山本氏 ॠ $^{3}$ 綜説がある程度である。現在は共 沸蒸溜, 抽出蒸溜の応用が各方面で盛んに活用されるよ らになってきた傾向にあるので筆者らは多成分系気液平 衡の一般的な関保を与えることは意義あることと考える 次第である。そこで Guggenheim"が展開したところ の 2 成分系正則溶夜の理論を多成分系に払張してその気 液平衡関係の表現を試み，さらに 多成分共沸物の解析を行ったので ここに報告する。

\section{§2. 液相における仮想分 子配置と気液平衡関 係式の基礴的䚽道に つい}

$i$ 分子 $N_{i}$ 個を含む $n$ 成分系の 液相に対して最む簡単な対の分子 配置の液相モデルを仮想すれば対 の種類，対の数、対の有するニネ ルギーは Guggenheim と同様に

Table 1 のごとくなる。

* 昭和 33 年 10 月 27 日受理

** 名古屋工莱大学工䅈化学教室

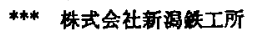

*****株式会社蔣永田造船所
山田幾穗**吉田高年**

広 瀬 俊 彦***.川 瀬

修****
ここで $w_{i j}$ は Hildebrand が与えたij分子間の分子 交換エネルギーである。

与克られた $X_{i j}$ に対して系の配置のエネルギーE。は (1) 式のごとくなる。

$$
E_{\mathrm{c}}=-\sum_{i} N_{i} Y_{i}+\sum_{i j} X_{i j} w_{i j} \quad(i \neq j)
$$

ここで $\sum_{i j} X_{i j} w_{i j}(i \neq j)$ は混合のエネルギーとなる。

さて， $X_{i j}$ の計算方法としては，ます系の分子が完全 にランダムであるという零次近似法を仮定するとし $X_{i j}$ の平衡值を $\bar{X}_{i j}$ とすれば Guggenheim の方法によって 以下のことき連立方程式をうる。

$$
\begin{gathered}
\left(N_{i}-\sum_{i} \bar{X}_{i k}(i \neq k)\right)\left(N_{j}-\sum_{k} \bar{X}_{j k}(j \neq k)\right) \\
=\bar{X}^{2}{ }_{i j} \quad(i \neq j) \quad(i, j=1,2, \cdots \cdots, n)
\end{gathered}
$$

これを解けば

$$
\bar{X}_{i j}=N_{i} N_{j} / N
$$

となる。ただし $\Sigma N_{i}=N$ である。したがって（1）式 は

$$
E_{0}=-\sum_{i} N_{i} Y_{i}+\sum_{i j} N_{i} N_{j} w_{i j} / N \quad(i \neq j)
$$

となる。

配置の分配函数 $\psi$ は定義により 


$$
\phi=\left(\exp \cdot \sum_{i} N_{i} Y_{i} / k T\right)\left(\sum_{i j} \exp \left(-X_{i j} w_{i j} / k T\right)\right)
$$

である。配圈の数 $\phi$ は, $\phi=N ! / N_{1} ! N_{2} ! \cdots \cdots N_{n}$ ! であ ク $X_{i j}$ の平均值を $\overline{\bar{X}}_{i j}$ とすれば（5）式は，

$$
\begin{aligned}
\psi=\left(\exp . \sum_{i} N_{i} Y_{i} / k T\right) \frac{N !}{N_{1} ! N_{2} ! \cdots \cdots N_{n} !} \\
\quad \times\left(\exp . \sum_{i j}-\bar{X}_{i j} w_{i j} / k T\right) \quad(i \neq j)
\end{aligned}
$$

となる。配置の自由エネルギー $F_{0}$ は， $F_{0}=-k T \ln \psi$ で与えられるゆえ， $N ! / N_{1} ! N_{2} ! \cdots \cdots N_{n}$ ! の項に Stirling の公式を適用すれば，

$$
\begin{gathered}
F_{c}=-\sum_{i} N_{i} Y_{i}+k T \sum N_{i} \ln N_{i} / N+\sum_{i j} \overline{\bar{X}}_{i j} w_{i j} \\
(i \neq j)
\end{gathered}
$$

で与えられる。ここで第二項は理想溶液の混合の自由エ ネルギー，第三項は過剩自由エネルギーである。

なお $\bar{X}_{i j}$ と $\bar{X}_{i j}$ との間には， $E_{e}$ と $F_{0}$ に関して，

$$
E_{c}=F_{c}-T\left(\partial F_{c} / \partial T\right)
$$

であるから，過剩の項から

$$
\begin{aligned}
& \sum_{i j} \bar{X}_{i j} w_{i j}(i \neq j) \\
& \quad=\sum_{i j} \overline{\bar{X}}_{i j} w_{i j}(i \neq j)-T\left(d \sum \overline{\bar{X}}_{i j} w_{i j} / d T\right)(i \neq j)
\end{aligned}
$$

そなり

$$
\bar{X}_{i j} w_{i j}=\overline{\bar{X}}_{i j} w_{i j}-T\left(d \overline{\bar{X}}_{i j} w_{i j} / d T\right)
$$

すなわち

$$
\overline{\bar{X}}_{i_{j}}=T \int_{0}^{1 / T} \bar{X}_{i j} d\left(\frac{1}{T}\right)
$$

を5る。さて $\bar{X}_{i j}$ は（3）式によって示されたごとく温 度に無関係であるから， $\overline{\bar{X}}_{i j}=\bar{X}_{i j}$ となり，配置の自由 エネルギーは,

$$
\begin{gathered}
F_{\mathrm{c}}=-\sum_{i} N_{i} Y_{i}+k T \sum_{i} N_{i} \ln N_{i} / N+\sum_{i j} N_{i} N_{j} w_{i j} / N \\
(i \neq j)
\end{gathered}
$$

で与えられる。ここで最終項は過剩自由エネルギーを示 す。気液平衡関係にあるとき， $i$ 成分の活量係数 $r_{i}$ と過 剩自由エネルギー $F_{0}{ }^{\circ}$ との間炕,

$$
R T \ln \gamma_{i}=\left(\partial F_{i} \cdot \partial N_{i}\right)_{j \cdot T \cdot P}
$$

の関俰があるから，（12）式の右辺を $N_{i}$ で偏貒分し $N_{i}$ $=N x_{i}$ の関係を代入すれば,

$R T \ln \gamma_{i}=\sum_{p}\left(1-x_{i}\right) x_{p} w_{i p}(i \neq p)-\sum_{p q} x_{p} x_{q} w_{p q}\left(\begin{array}{l}p \neq q \\ p, q \neq i\end{array}\right)$

となる。

\section{3. 従来の式との比校について}

van $\operatorname{Laar}^{2}$ 形式の 2-suffix の式によれば $F_{0}$ ・対し $\tau$

$$
\begin{array}{rl}
F_{\bullet}=2 & .3 R T\left(\sum_{i, j} x_{i} x_{j} A_{j-i}(i \neq j)+\sum_{j k} x_{j} x_{k} A_{j-k} \frac{A_{k-i}}{A_{i-k}}\right. \\
\left.\left(\begin{array}{l}
j \neq k \\
j, k \neq i
\end{array}\right)\right) \times\left(\sum_{j} x_{j} \frac{A_{j-i}}{A_{i-j}}\right)^{-1}
\end{array}
$$

が与交られている。ここで $A_{i-j}=A_{j-i}=A_{i j}$ と括けば

$$
F_{0}^{\circ}=2.3 R T N \sum_{i, j} x_{i} x_{j} A_{i j}(i \neq j)
$$

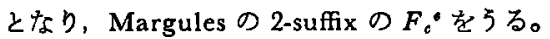

(12）式の最終項と（16）式を比較すれば,

$$
A_{i j}=w_{i j} / 2.3 R T
$$

をうる。さらに Perry ${ }^{5}$ によれば定数 $A_{i j}$ の温度变化に 対して $A_{i-j}=A_{j-i}$ の場合

$$
d A_{i j} / d T=L_{i}{ }^{0} / 2.3 R T^{2}=L_{j}{ }^{0} / 2.3 R T^{2}
$$

で与えられている。したがって (14) 式を Margulesの 2-suffix の式と比較する場合，(17）（18）の両式より明 らかなことく定数 $w_{i j}$ は $A_{i j}$ に比して温度による変化が 少なく先の考虑が省け，4成分以上の系についてもきわ めて簡略化されていると考えられる。 $w_{i j}$ は実験的汇決 められる值であり， $n$ 成分阔して $n C_{2}$ 個存在する。し たがって3.成分系の場合は 1 組の実験データで (14) 式 の連立方程式を解けば 3 個の $w_{i j}$ が求められる。しかし 4 成分以上の系では，このよ5な方法は困難であるため Margules の式の $A_{i j}$ を求める方法と同様に $x_{j}$ の極限值 をとれば

$$
R T \ln _{x_{j} \rightarrow 1} \gamma_{i}=w_{i j}
$$

となり $w_{i j}$ をる。

\section{4.（14）式の一般的な適用性について}

(17)，(18）の両式によって明らかなことく（14）式が 適用される采はすべての $w_{i j}$ に相当する $A_{i j}$ において $L_{i}{ }^{0}=L_{j}{ }^{0}$ ， あるいは $L_{i}{ }^{0} \fallingdotseq L_{j}{ }^{0}$ を满足される系である。 山本氏光に上れば Margules の 2-suffix の式は“可成有 用で適合する系が多い。ただし 2 成分采が対称形である ことが必要”とされている。したがって（14）式も各 $i-j$ 飞対して2成分系の場合の $R T \ln r_{i}-x_{i}, \quad R T \ln$ $r_{j}-x_{j}$ が対称形でないならばよく適合する系とはいえな い。以上の条件を満足する系はラウールの法則からわず かに偏位する系が適当と思われる。すっとも(14) 式の 誘尊にあたって2つの大きな仮定をおいた。すなかち

i）液相を“対”の仮想モデルとした。

ii）分子配置が完全にランダムであるとした。 この大きな仮定が適用範囲を前述のことく制限したるの と考光られる。いまここで $w_{i j}$ の值をメチルエチルケト ソーnーヘブタンートルエン6) 系について調査してみよう。

Table 2 に拈いて各 $x_{i}$ K対寸る $w_{i j} / R$ が示される。 $w_{i j} / R$ の值は必寺しす桓常を示しているとはい良ない。 
Table 2 Value of $w_{i j} / R$ in methyl-ethylketone (1)-n-heptane (2)-toluene (3)

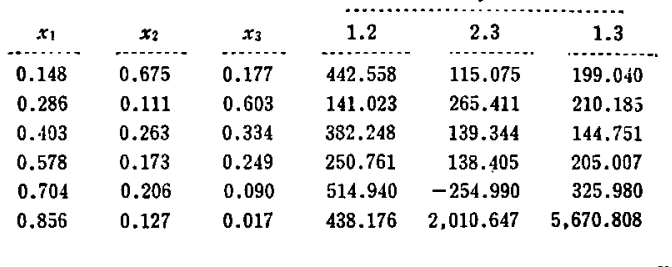

同様に $j$ 成分飞対して

$$
\begin{aligned}
\Delta S_{j}\left(T_{j}{ }^{0}-T\right)= & \sum_{p}\left(1-x_{j}\right) x_{p} w_{j p}(i \neq j) \\
& -\sum_{p q} x_{p} x_{q} w_{p q}\left(\begin{array}{l}
p \neq q \\
p, q \neq j
\end{array}\right)
\end{aligned}
$$

をろる。ここで(21)，(22）の両式より $T$ を消去すれば $T_{i}{ }^{0}-T_{j}{ }^{0}$

$$
\begin{aligned}
= & \left\{\sum_{p}\left(1-x_{i}\right) x_{p} w_{i p}(i \neq p)-\sum_{p q} x_{p} x_{q} w_{p q}\left(\begin{array}{c}
p \neq q \\
p, q \neq i
\end{array}\right)\right\} \Delta S_{i}^{-3} \\
& -\left\{\sum_{p}\left(1-x_{j}\right) x_{p} w_{i p}-\sum_{p q} x_{p} x_{q} w_{p q}\left(\begin{array}{c}
p \neq q \\
p, q \neq j
\end{array}\right)\right\} \Delta S_{j}^{-1}
\end{aligned}
$$

\begin{tabular}{|c|c|c|c|c|c|}
\hline $\begin{array}{l}\text { Components } \\
\text { of system }\end{array}$ & $\begin{array}{l}\text { B. } \mathrm{P} \\
{\left[{ }^{\circ} \mathrm{C}\right]}\end{array}$ & $\begin{array}{l}\text { B.P. } \\
\text { difference }\end{array}$ & $w_{i j} / \Delta S_{i}$ & $w_{i j} / \Delta S_{j}$ & azeotropes \\
\hline \multirow{3}{*}{$\begin{array}{l}\text { ethanol- } \\
\text { cyclohexane- } \\
\text { water }\end{array}$} & \multirow[t]{3}{*}{62.1} & $\Delta T_{21}=2.2$ & 69.4 & 53.6 & \multirow[t]{3}{*}{ exist } \\
\hline & & $\Delta T_{32}=19.2$ & 97.4 & 115.9 & \\
\hline & & $\Delta T_{13}=-21.4$ & 26.0 & 28.2 & \\
\hline \multirow{3}{*}{$\begin{array}{l}\text { iso-propanol- } \\
\text { cyclohexane- } \\
\text { water }\end{array}$} & \multirow[t]{3}{*}{63.8} & $\Delta T_{21}=-1.2$ & 68.7 & 50.7 & \multirow[t]{3}{*}{ exist } \\
\hline & & $\Delta T_{32}=19.2$ & 93.5 & 111.3 & \\
\hline & & $\Delta T_{13}=-17.5$ & 37.3 & 42.4 & \\
\hline \multirow{3}{*}{$\begin{array}{l}\text { allyl alcohol- } \\
\text { cyclohexane- } \\
\text { water }\end{array}$} & \multirow{3}{*}{65.2} & $\Delta T_{21}=-16.3$ & 94.7 & 73.0 & \multirow{3}{*}{ exist } \\
\hline & & $\Delta T_{31}=19.2$ & 90.0 & 107.2 & \\
\hline & & $\Delta T_{13}=-2.9$ & 25.1 & 27.4 & \\
\hline \multirow{3}{*}{$\begin{array}{l}\text { ethanol- } \\
\text { benzene- } \\
\text { water }\end{array}$} & \multirow[t]{3}{*}{64.8} & $\Delta T_{21}=1.8$ & 55.4 & 91.5 & \multirow[t]{3}{*}{ exist } \\
\hline & & $\Delta T_{32}=19.8$ & 106.9 & 128.8 & \\
\hline & & $\Delta T_{19}=-21.6$ & 49.8 & 53.0 & \\
\hline \multirow{3}{*}{$\begin{array}{l}i \text {-propanol- } \\
\text { benzene- } \\
\text { water }\end{array}$} & \multirow[t]{3}{*}{65.3} & $\Delta T_{21}=-1.7$ & 65.7 & 48.5 & \multirow[t]{3}{*}{ exist } \\
\hline & & $\Delta T_{32}=19.7$ & 89.7 & 104.6 & \\
\hline & & $\Delta T_{13}=-18.5$ & 31.6 & 27.8 & \\
\hline \multirow{3}{*}{$\begin{array}{l}\text { allyl alcohol- } \\
\text { benzene- } \\
\text { water }\end{array}$} & \multirow[t]{3}{*}{67.8} & $\Delta T_{21}=-17.3$ & 109.8 & 79.6 & \multirow{3}{*}{ exist } \\
\hline & & $\Delta T_{32}=19.8$ & 85.6 & 101.8 & \\
\hline & & $\Delta T_{13}=-2.5$ & 42.7 & 42.7 & \\
\hline \multirow{3}{*}{$\begin{array}{l}\text { methanol- } \\
\text { acetose- } \\
\text { water }\end{array}$} & \multirow[t]{3}{*}{61.7} & $\Delta_{21}=8.2$ & -6.1 & -6.9 & \multirow[t]{3}{*}{ none exist } \\
\hline & & $\Delta_{32}=35.3$ & 31.2 & 31.1 & \\
\hline & & $\Delta_{13}=-43.5$ & 64.8 & 57.6 & \\
\hline
\end{tabular}

Table 3 Azeotropic relations in tertiary systems

となる。ここで右辺は $x_{j}=1$ のと き最大値をとり $x_{i}=1$ のとき最小 値をとるから $T_{i}{ }^{0}-T_{j}{ }^{0}$ は共沸現 象に対して

$$
\begin{aligned}
& -w_{i j} \Delta S_{j}{ }^{-1} \leqq T_{i}{ }^{0}-T_{j}{ }^{0} \\
& \leqq w_{i j} \Delta S_{i}{ }^{-1}
\end{aligned}
$$

を5る。この関係は 2 成分系に対 し益子らが導いた関係式と同じ のである゙。したがって系のすべ ての ij の結合せについて (24) 式 が成立すれば多成分系共沸物が形 成されることになる。3 成分系に 例をとり，この関係名を表わせば

Table 3 のごとくなる。

\section{ii）共沸系の $\boldsymbol{w}_{i j}$ の恒常性に วい:}

（14）式を 3 成分系に例をとり w汸求めれば,

$$
w_{12}=R T\left|\begin{array}{ccc}
\ln \gamma_{1} & -x_{2} x_{3} & \left(1-x_{1}\right) x_{3} \\
\ln \gamma_{2} & \left(1-x_{2}\right) x_{3} & -x_{1} x_{3} \\
\ln \gamma_{3} & \left(1-x_{3}\right) x_{2} & \left(1-x_{3}\right) x_{1}
\end{array}\right|
$$$$
\times\left|\begin{array}{ccc}
\left(1-x_{1}\right) x_{2} & -x_{2} x_{3} & \left(1-x_{1}\right) x_{3} \\
\left(1-x_{2}\right) x_{1} & \left(1-x_{2}\right) x_{3} & -x_{1} x_{3} \\
-x_{1} x_{2} & \left(1-x_{3}\right) x_{2} & \left(1-x_{3}\right) x_{1}
\end{array}\right|^{-1}
$$

をらる。Table 1 に示されたよ5に $w_{i j}$ は他成分によっ て影䈏されないとした。るしこの仮定が正しければ 1,2 を含む 3 成分共沸系の共沸温度 $T$ ，共沸組成 $x_{i}$ が与之 られれば（25）式の分母 $\Delta$ と分子 $M$ をブロットすれば 原点をとおる直線関係をうるはずである。この関係はデ ータによって整理すれば Fig. 1〜3のような值線関係を 示した。すなわら第 3 成分を同族系に選べば良好な直線 関係が得られ $w_{i j}$ に恒常性が共沸点に和いて成立したこ とになる。

iii）共沸温度による共沸組成の変化

いま（14）式について $R T \ln \gamma_{i}, R T \ln \gamma_{i+1}$ の差をと れば $x$ に関する 2 次項は消去される。 


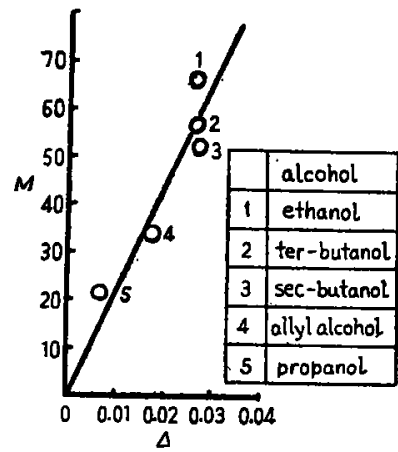

Fig. $1 \quad \mathrm{CCl}_{4}-\mathrm{H}_{2} \mathrm{O}$-Alcohols system

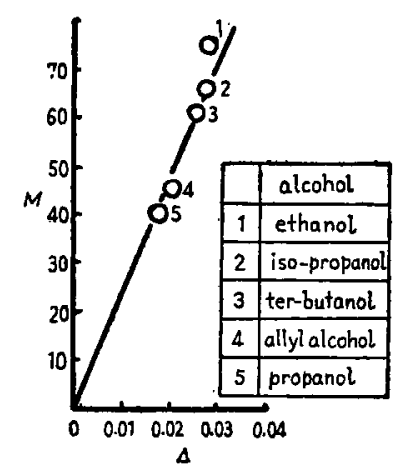

Fig. 2 Cyclohexane- $\mathrm{H}_{2} \mathrm{O}$-Alcohols systems

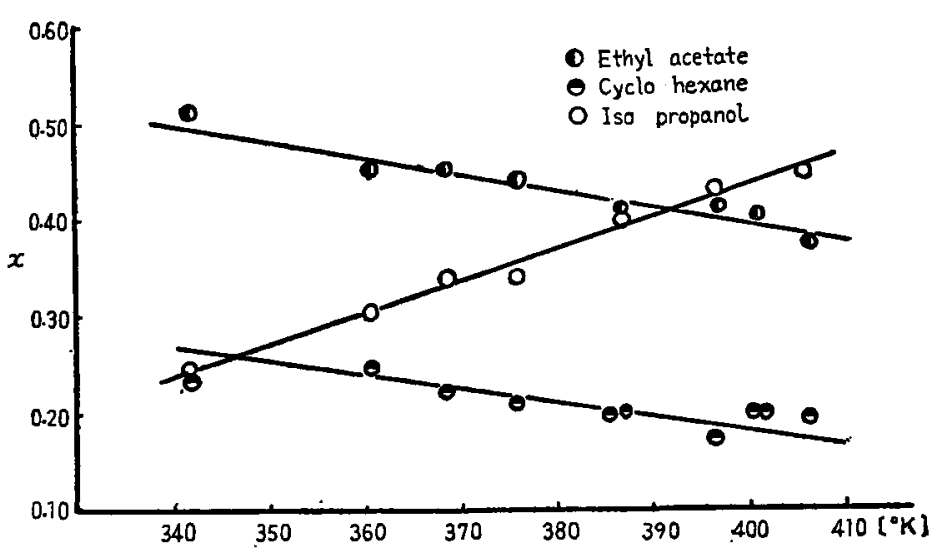

Fig. 4 Ethyl acetate-Cyclohexane-Isopropanol system

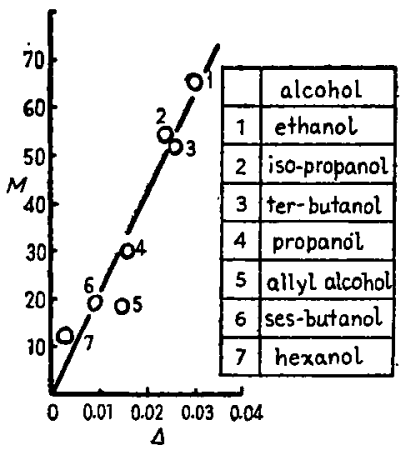

Fig. $3 \quad \mathrm{C}_{6} \mathrm{H}_{6}-\mathrm{H}_{2} \mathrm{O}$-Alcohols system

ル系 3 成分共沸物に対して頼実氏 のデータ9を借用して整理すれば Fig. 4 のごとき直線関係をらる。 iv) 共沸点の Break Point と 共沸温度の推定について

（27）式を $x_{i}$ について解いた結 果, それぞれの $i$ について $n$ 個の $T$ の一次式が得られる。そして $x_{i}=1$ または $x_{i}=0$ の $2 n$ 個の $T$ の中で最初の共沸温度にもっとも 近い伯が, Break Point となり $n$ 成分共沸物は破壞され $n-1$ 成分 系共沸物を形成するのであ。

ここで（27）式を解いて5る $x_{i}$ を（14）式に代入すれば，(14）式
$R T \ln \gamma_{i} / \gamma_{i+1}$

$=\left(x_{i+1}-x_{i}\right) w_{i, i+1}+\sum_{p}\left(w_{i p}-w_{i+1, p}\right) x_{p}(i, i+1 \neq p)$

を5る。これと $\sum x_{i}=1$ を組合せれ代次式を5る。

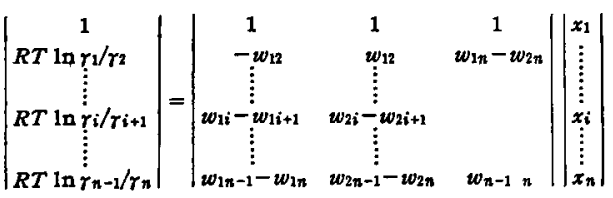

（27）式を $x_{i}$ について解けば $x_{i}$ は $R T \ln \gamma_{i} / \gamma_{i+1}$ の一 次函数となる。そして

$$
R T \ln \gamma_{i} / \gamma_{i+1}=R T \ln P_{i+1} / P_{i}
$$

であり $\ln P_{i}, \ln P_{i+1}$ に対して Clausius-Clapeyron $の$ 型 $\ln P_{i}=A_{i}+B_{i} / T$ を適用すれば

$$
R T \ln \gamma_{i} / \gamma_{i+1}=\left(A_{i+1}-A_{i}\right) T+\left(B_{i+1}-B_{i}\right)
$$

となり $x_{i}$ は $T$ の一次函数として表わすことができる。 いま酢酸エチルーシクロへキサンーiso プロピルフルコー
は $w_{i j}$ およよ゙ $T$ の二次函数となり，これを $T$ について 解けば与えられた $w_{i j}$ における共沸温度 $T$ が推定され る。そして $T$ の実根が得られない場合は系共沸点を有 してないと推定される。これに関する検討は後日に述へ ることにする。

\section{\$6. 結 言}

筆者らは多成分系共沸物に対して“対”の夜相モデ ルを仮想し配置のエネルギーが気液平衡関係にある活量 係数を求める式を Guggenheim の方法によって導い た。その結果 van Laar 形式の 2-suffix の式で $A_{i-j}=$ $A_{j-i}=A_{i j}$ ，すなわら Margules 形式の 2-suffix の式と 同型であるが $A_{i j}=w_{i j} / 2.3 R T$ なる関保を導いた。こ れは $w_{i j}$ が $A_{i j}$ に比して温度による变化が少ないという 利点が推定される。誘導された式を多成分系共牒物に適 用し，多成系共沸物の形成条件を導いた。また第 1 ，第 2 成分を固定し第 3 成分が同族釆列で共沸物を形成する 
場合共沸点に括ける $w_{12}$ に恒常性が成立することを認め た。そして共沸組成 $x_{i}$ が温度 $T$ の一次函数であること を䤏酸エチルーシクロヘキサン-iso プロピルフルコール 系について認めた。要するに液相烧して“対”の分子 配置，分子のランダム配珇を仮定して理論的に導いて得 られた式は Margules の 2-suffix の形成々類型であり総 ての 2 成分の組合せに対して $x_{i}-R T \ln \tau_{i}$ が対称形の 多成分系に上く道用され，可成有用であると推定された がこの判定は非常にむずかしく，蜜ら共沸点といら気液 平衙関保の特異点によく適合されることが認められた。

[付記］ミ5 の部分は投稿後審查中に追加したるのであ ることを继りする。

\section{Nomenclature}

$N$ : number of molecules

$\boldsymbol{Z}$ : coordination number

$w$ : intermolecular exchange energy given by Hildebrand

$Y$ : configurational energy per molecule

$X$ : number of pairs consisting of $i$ and $j$ molecules

$\bar{X}$ : equilibrium value of $X$

$\overline{\bar{X}}$ : average value of $X$

$E_{\theta}$ : configurational energy

$F_{\varepsilon}$ : configurational free energy

$\psi$ : partition function

$T:$ absolute temperature

\author{
$P$ : vapor pressure \\ $R$ : gas constant \\ $x:$ molfraction in 1 iquid phase \\ $A$ : van Laar's and Margules' coefficient \\ $L^{0}$ : heat of dilution \\ $k$ : Boltzmann constant \\ $r:$ activity coefficient \\ $\Delta H$ : heat of vaporization \\ $\Delta S$ : entropy of vaporization \\ $A$ and $B$ are constants when calculated by \\ Clausius-Clapeyron equation \\ subscription : kind of components
}

\section{Literature cited}

1) Hirata, M. : Chem. Eng. (Japan), 13, 138 (1949) ; 14, 16 $(1950) ; 65(1950) ; 15,72$ (1951)

2) Woh1, K. : Trans. Am. Inst. Chem. Eng., 41, 539 (1945); Chem. Eng. Prog.49, 218 (1953)

3) Yamamoto, H. : Chem. Eng. (Japan), 20, 251 (1956)

4) E. A. Guggenheim: "Mixtures," p. 29, calendor, Oxford (1952)

5) Perry, J. H. : Chem. Eng. Hand Book, D. 529, McGrawHill

6) Ju-chin-Chu : Distillation equilibrium data, Reinhold New York (1950)

7) Masuko, Y. \& Yoshimoto, T. : Reports of the Govern ment Cehm. Ind. Res. Inst.. Tokyo, 52, 158 (1957)

8) Horsly : Anal. Chem., 19, 601 (1947)

9) Yorizane M. : Presented at the meeting held by the society of Chem. Eng. (Japan), at Wakayama (Nov. 1958)

\title{
Vapor-Liquid Equilibrium Relations in Multi-Component Systems Expressèd by Means of the Zeroth Approximation and Analysis of Multi-Azeotropes
}

\author{
Ikuho Yamada, ${ }^{*}$ Takatoshi Yoshida, \\ Toshihiko Hirose** and Osamu Kawase***
}

The authors have obtained the vapor-liquid equilibrium relations in multi-component systems, assuming completely random mixing for molecular distribution and molecular configurations having pairs in liquid phase called the zeroth approximation. The final result obtained with respect to $r_{i}$ is as follows :

$$
R T \ln \gamma_{i}=\sum_{p} x_{p}\left(1-x_{i}\right) \omega_{i p}(i \neq p)-\sum_{p p} x_{p} x_{q} \omega_{p q}\left(\begin{array}{c}
p \neq q \\
p q \neq i
\end{array}\right)
$$

The above relation gives an equation similar to Margules' formula of type 2-suffix as weil as to van Laar's formula of type 2 suffix : $A_{i-j}=A_{j-i}=A_{i j}$, which can be transformed into $A_{i j}=\omega_{i j} / 2,3 R T$.

The result obtained presumably holds well in case $L_{i}{ }^{0}=L_{j}{ }^{0}$ or $L_{i}{ }^{0} \fallingdotseq L_{j}{ }^{0}$, where $i$ is $1,2, \cdots \cdots, n$, and symmetrica 1 systems.

Analysis of the multi-azeotrope by means of the equation thus obtained gives the following results :

i) In multi-azeotropes, the following relations must hold:

$$
-\omega_{i j} \Delta S_{j}{ }^{-1} \leqq T_{i}{ }^{0}-T_{j}{ }^{0} \leqq \omega_{i j} \Delta S_{i}{ }^{-1}
$$

ii) The values of $\omega_{i j}$ are constant when the components keep homologous series to one another.

iii) Azeotropic compositions $x_{i}$ are given by linear functions of $T$.

\footnotetext{
- Nagoya Institute of Technology ** Niigata-telkko-jyo Co. Ltd *** Fujinagata-zosen.jro Co. Ltd
} 